\title{
$\mathfrak{I a} \mathfrak{d} \mathfrak{e} \mathfrak{e n b} \mathfrak{d}$
}

$$
\text { fä } r
$$

Die vaterlánbirde (s)efdidte. 



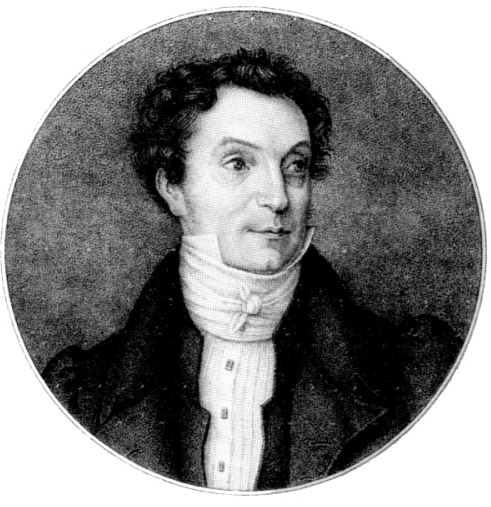

Rudbert.

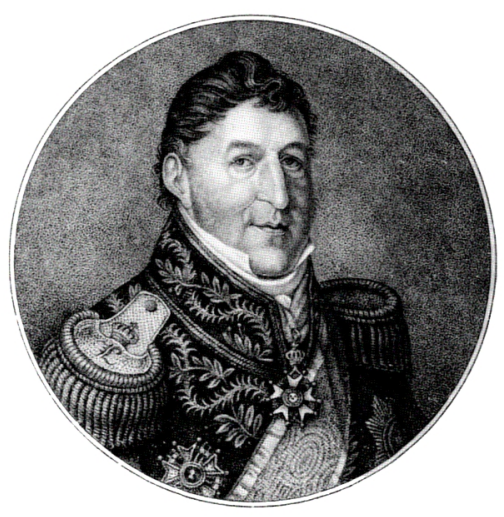

Stiohoner.

CHelmsauer. fe. 



\title{
$\mathfrak{I} \mathfrak{a} \mathfrak{i} \mathfrak{d} \mathfrak{e} \mathfrak{n} \mathfrak{b} \mathfrak{u} \mathfrak{d}$
}

\author{
fúr

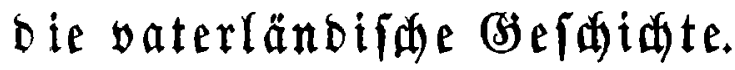 \\ fyerassegeba \\ wor
}

3oleph freiberru von Gotmagr.

XXXII. Sahrgang ber gefammten und

XV. ber neuen golge.

1844.

Mit 4 Bilbnifett.

Berlin bel \&. Reimer. 